\title{
Femoroacetabular impingement: a consideration in younger adults with hip pain
}

\author{
Heather Hansen MD, Regina Taylor-Gjevre MD MSc, Haron Obaid MD, Rajiv Gandhi MD MS, Anthony King MD
}

$\mathrm{A}$ 32-year-old woman with a family history of rheumatoid arthritis was referred to a rheumatology clinic with symptoms of right knee and hip discomfort. These joint symptoms had been progressive over the last 10 or more years. Her symptoms were predominantly mechanical rather than inflammatory in description, with worsening symptoms with use of her joints, pain that was aggravated by flexion and rotation of her hip, and no substantial morning stiffness. She had been taking nonsteroidal anti-inflammatory drugs and had received chiropractic treatments for her symptoms with limited benefit. Her physical examination was notable for restricted range of motion at the right hip. She had pain with the hip impingement test, in which the hip is flexed and internally rotated. On the remainder of her examination, there was no evidence of inflammatory arthritis. Her presentation and examination were not consistent with rheu matoid arthritis, despite her positive family history. Radiography of the hips was performed (Figure 1). A diagnosis of femoroacetabular impingement was made, and she was subsequently seen by an orthopedic surgeon. Hip arthroscopic procedures were discussed, as was acetabular osteotomy. However, the patient chose not to pursue these options at the time.

\section{Discussion}

Hip pain is a common symptom seen in primary care and musculoskeletal care clinics. Osteoarthritis of the hip is prominent in the differential diagnosis of hip pain. It is often seen in the older patient but occasionally may be seen in patients less than 50 years of age. ${ }^{1}$ Multiple risk factors or associations have been linked with the de velopment of hip osteoarthritis (Box $1^{1-4}$ ). In a younger patient, it is important to consider dis orders related to childhood hip pathology or to anatomical abnormalities. ${ }^{1,2}$ Anatomical abnormalities may be more common than perhaps appreciated and can include femoral and acetabular dysplasia, retroverted acetabulum, pistol grip deformity of the femur, coxa profunda (deep acetabular socket) and acetabular protrusion (a central acetabular defect resulting from migration of the femoral head). ${ }^{1,3-5}$ Such anatomical abnormalities may lead to a prearthritic state known as femoroacetabular impingement, ${ }^{4}$ which has been suggested to predispose to subsequent development of osteoarthritis. ${ }^{1,4-7}$ Recognition of femoroacetabular impingement may be of particular importance among primary care physicians and other musculoskeletal care providers, because early recognition and intervention may potentially delay or even prevent the development of osteoarthritis. However, despite the understanding that femoroacetabular impingement may predispose to subsequent osteoarthritis, the natural history of untreated femoroacetabular impingement and the longterm results after surgical intervention are still incompletely elucidated.

\section{What is femoroacetabular impingement?}

Femoroacetabular impingement results when there is an abnormal anatomical relation between the femoral head or neck and the acetabulum,
Competing interests:

Rajiv Gandhi has received payment for lectures from Smith \& Nephew. No other competing interests were declared.

This article has been peer reviewed.

Correspondence to: Regina Taylor-Gjevre, r.gjevre@usask.ca

CMAJ 2013. DOI:10.1503 /cmaj.120827

\section{- Ker POINTS}

- Femoroacetabular impingement results when there is an abnormal anatomical relation between the femoral head or neck and the acetabulum.

- It is a potential prearthritic state, which may progress over time to degenerative changes and osteoarthritis.

- This condition may be suspected in a younger adult who presents with hip or groin discomfort, which can be exacerbated by hip flexion.

- Hip impingement tests are helpful in making the diagnosis, and plain radiography and magnetic resonance imaging are useful imaging modalities.

- Although the natural history of femoroacetabular impingement is still unclear, early recognition and orthopedic referral may be important factors in delaying the progression of osteoarthritis. 


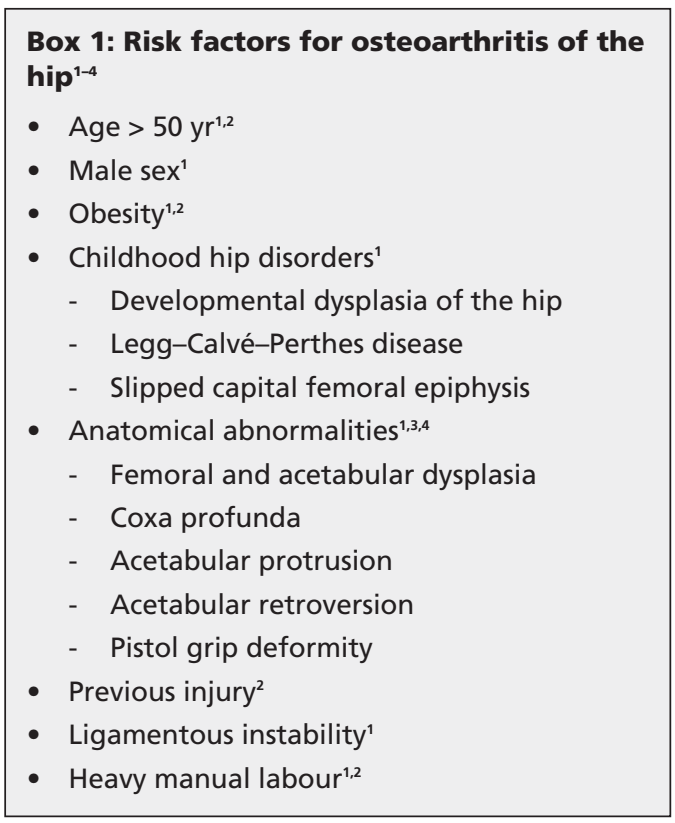

which leads to increased contact between these areas in hip flexion..$^{5}$ Over time, this may lead to degenerative changes and osteoarthritis. ${ }^{5}$ Proximal femoral configuration in an adult is determined by growth of the physes, muscle pull, forces transmitted across the joint with weight bearing, joint nutrition and circulation. ${ }^{8}$ Normal growth and development of the acetabulum is determined by a balance of growth of the acetab- ular and triradiate cartilages, and a well-located and centred femoral head. ${ }^{8}$

Femoroacetabular impingement has been classified into 3 types: cam, pincer and a combination of both. Cam impingement results from a nonspherical femoral head with a prominent femoral neck (Figure 2). With range of motion, this prominence may be forced into the acetabulum resulting in acetabular cartilage delamination, tearing of the labrum and/or avulsion from the rim. Cam impingement tends to be seen in young, active men. ${ }^{5,6}$ In contrast, pincer impingement is caused by impingement of the acetabular rim and the femoral neck because of femoral head overcoverage (Figure 3). The femoral head is relatively normal, but the acetabulum is deep. This is most often seen in middle-aged, active women. ${ }^{4.5}$ Most patients, however, have a combination of the 2 types.

Because awareness of femoroacetabular impingement is relatively recent, the long-term natural history is incompletely understood. An association between femoroacetabular impingement morphology and acetabular cartilage damage has been described. ${ }^{9}$ What is less clear is the association of femoroacetabular impingement morphology with the development of future osteoarthritis. Hartofilakidis and colleagues ${ }^{10}$ observed 96 asymptomatic patients with femoroacetabular impingement over a mean of 18 years:

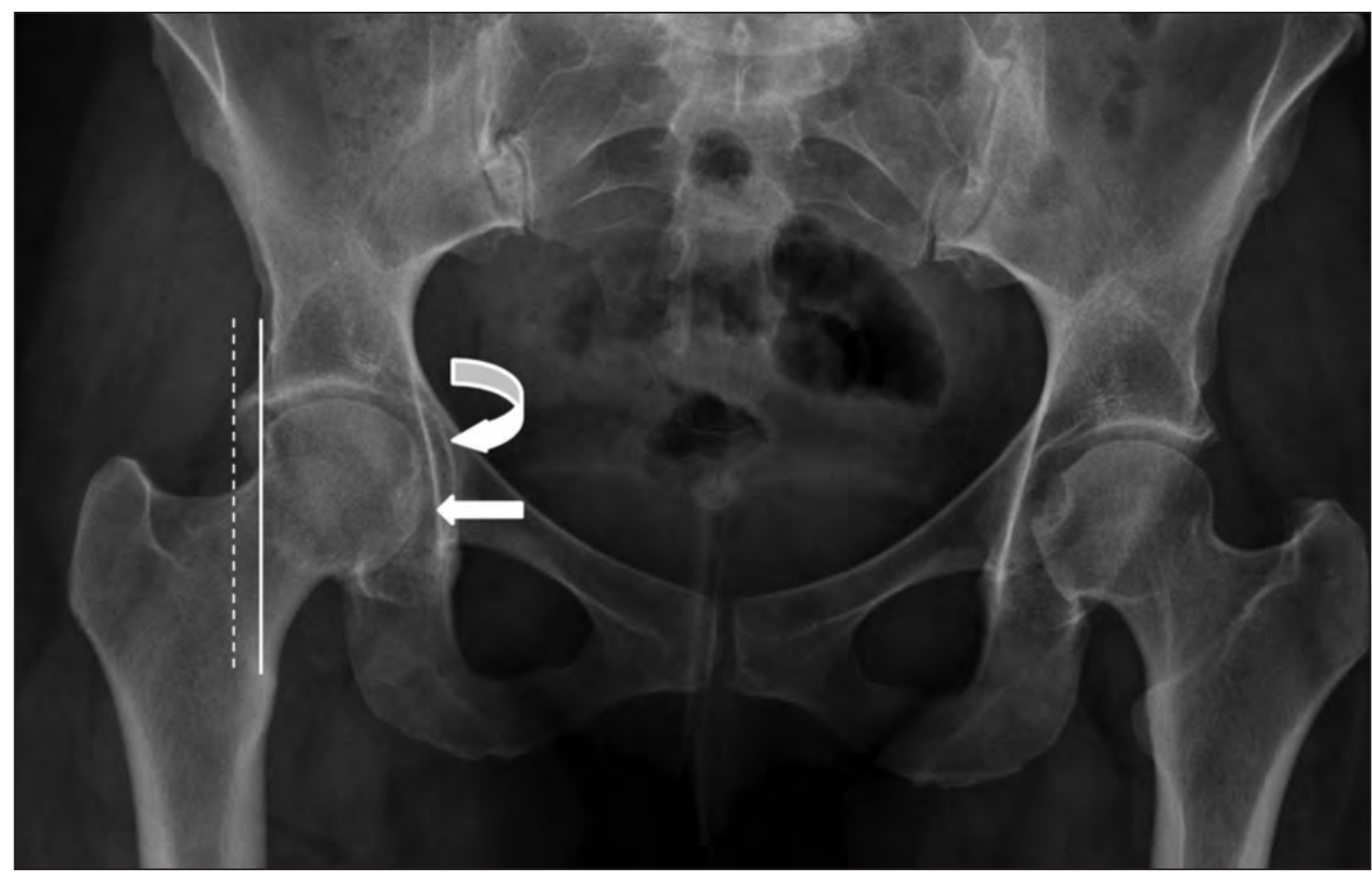

Figure 1: Frontal radiograph of the pelvis of a 32-year-old woman who presented with right-sided hip pain. There is coxa profunda (deep acetabular socket), which is shown by a medial shift of the acetabular fossa line (curved white arrow) in relation to the ilioischial line (solid white arrow). A line drawn along the superolateral margin of the femoral head (solid white line) is situated medial to the line drawn along the superolateral margin of the acetabulum (dashed white line), which is in keeping with the pincer form of femoroacetabular impingement. Compare with the normal morphology of the left hip joint. 
osteoarthritis developed in $18 \%$ of these patients during the observation period. Understanding the importance of this finding requires comparison with the development of primary hip osteoarthritis in the general population. In a systemic review of radiographic prevalence of primary hip osteoarthritis, Dagenais and colleagues ${ }^{11}$ reported on 39 studies in general adult populations. Prevalence estimates in these studies ranged from $0.9 \%$ (in China) to $27 \%$ (in the United States). The authors recognized differences between sexes, age groups, methods of diagnosis and, possibly, ethnic groups. Although the wide range of prevalence estimates reported by Dagenais and colleagues ${ }^{11}$ makes it difficult to place the findings of Hartofilakidis and colleagues ${ }^{10}$ into a clear context, it is worth noting that of the 39 studies explored in the systemic review, only 5 reported osteoarthritis prevalence rates equal to or greater than the rate described by Hartofilakidis and colleagues. ${ }^{10,11}$

\section{When should femoroacetabular impingement be suspected?}

The typical history for a patient with femoroacetabular impingement includes a gradual onset of groin pain. ${ }^{4,5}$ Initially, the pain is intermittent and may be exacerbated by excessive activity or

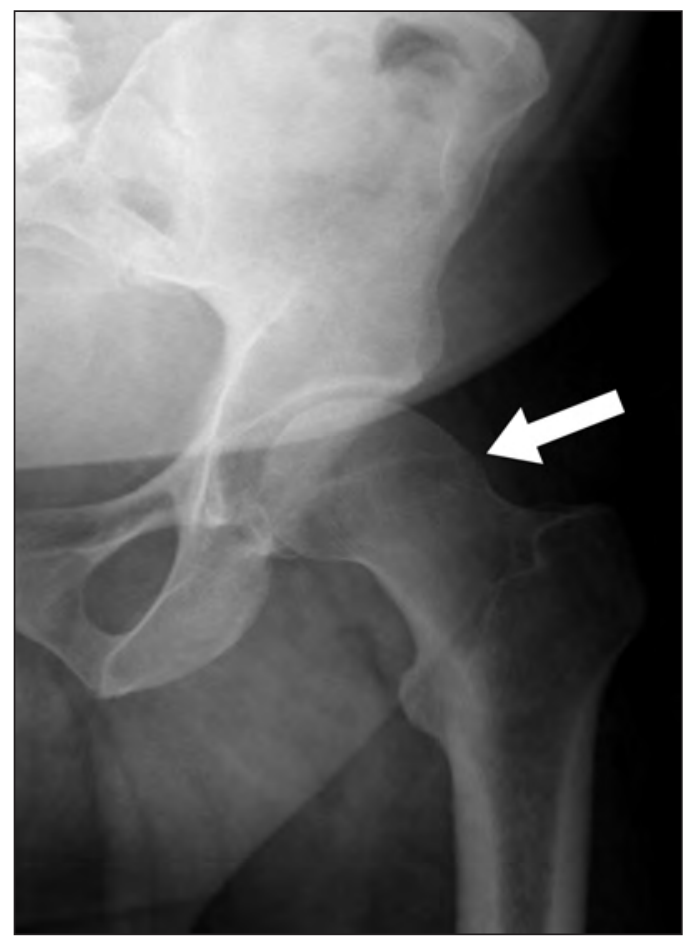

Figure 2: Frontal radiograph of the left hip showing cam impingement. Reduction in the femoral headneck offset angle indicates the presence of a bony bump (arrow). A bony bump signifies that the normal femoral head-neck offset junction is obliterated, creating a mechanical abnormality in which the bony bump impinges on the acetabular labrum. by hip flexion, including sitting. ${ }^{5}$ Patients may report mechanical symptoms such as clicking, locking and catching. ${ }^{6}$ The pain may be referred to the knee. ${ }^{5}$

Patients may additionally or alternatively report gluteal or trochanteric pain, which is most commonly thought to be a result of the aberrant gait mechanics secondary to abnormal hip morphology. ${ }^{4}$ However, gluteal pain can also relate to posterior acetabular impingement or posterior cartilage degeneration, often associated with pain at night. ${ }^{4}$ Although there are few symptoms that are specific for femoroacetabular impingement, younger age and symptoms related to hip flexion should raise suspicion of this diagnosis. Most patients do not report a loss of hip range of motion, but this finding is almost always seen on physical examination, secondary to anatomical abnormalities, pain or both. ${ }^{4}$

Other conditions, both soft-tissue and bony disorders, can present in a similar fashion to femoroacetabular impingement. The differential diagnosis is broad and should include entities such as sacroiliitis, degenerative disk disease, problems with the abductor muscles, osteonecro-

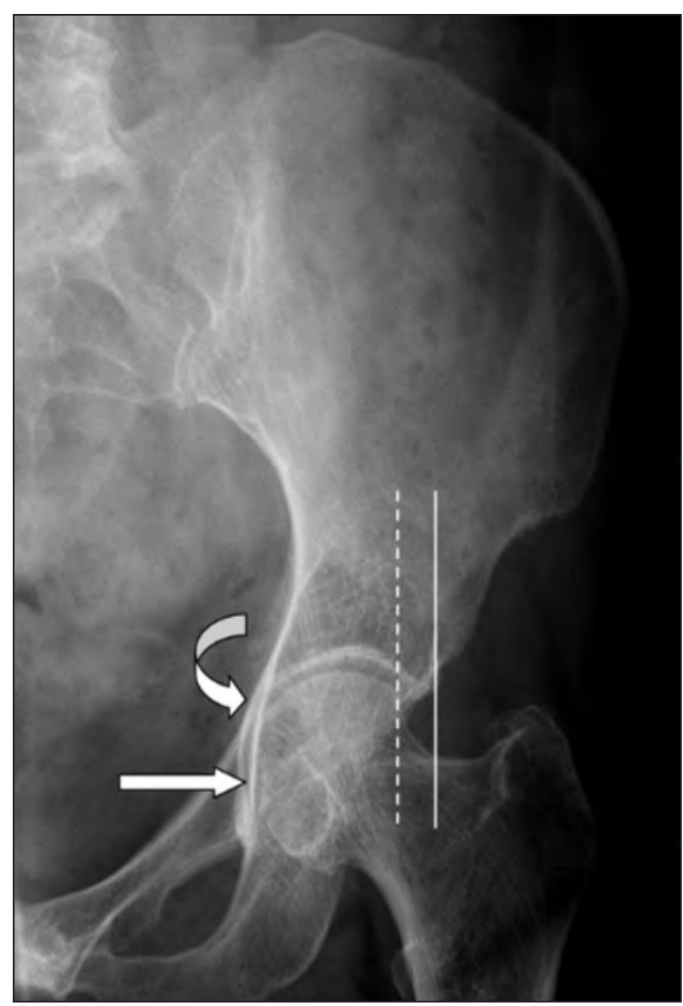

Figure 3: Frontal radiograph of the hip showing pincer impingement. The acetabular fossa (curved white arrow) is medial to the ilioischial line (straight white arrow). A line drawn along the superolateral margin of the femoral head (dashed white line) is situated medial to the line drawn along the superolateral margin of the acetabulum (solid white line), which is in keeping with the pincer form of femoroacetabular impingement. 
sis of the femoral head, psoas tendinitis, pubic rami fractures, stress fractures of the proximal femur, trochanteric bursitis, athletic pubalgia, snapping hip syndrome and traumatic acetabular labral tears. ${ }^{4,12}$

\section{What physical findings may be seen?}

It is important to keep the broad differential diagnosis of hip pain in mind when performing the physical examination. Differences in location of pain, range of motion, swelling and effusion, and tenderness (Box 2 ${ }^{12-14}$ ) should help narrow the diagnosis.

In femoroacetabular impingement, decreased range of motion is commonly seen with flexion, internal rotation and adduction on physical examination. ${ }^{5}$ Gait should be assessed and limb lengths measured. ${ }^{4}$ The limb can be assessed at rest for any clue of an anatomical abnormality, such as asymmetric external rotation of the legs that may be seen with acetabular retroversion, femoral retroversion, or femoral head and neck abnormalities. ${ }^{4}$ A complete examination of the spine and involved extremity should be performed.

\section{Are there any special tests?}

Special tests include the impingement test and the posterior impingement test ${ }^{4,5}$ (Figure $4^{6}$ ). The impingement test is a test for anterosuperior impingement. It is performed with the patient

\begin{tabular}{|c|c|c|c|c|c|}
\hline \multicolumn{6}{|c|}{ Box 2: Findings on physical examination of the hip for hip disorders ${ }^{12-14}$} \\
\hline Condition & $\begin{array}{l}\text { Location } \\
\text { of pain }\end{array}$ & $\begin{array}{l}\text { Range } \\
\text { of motion }\end{array}$ & $\begin{array}{l}\text { Swelling/ } \\
\text { effusion }\end{array}$ & $\begin{array}{l}\text { Bony } \\
\text { tenderness }\end{array}$ & $\begin{array}{l}\text { Soft-tissue } \\
\text { tenderness }\end{array}$ \\
\hline $\begin{array}{l}\text { Femoroacetabular } \\
\text { impingement }\end{array}$ & Groin & Varies & No & No & Possible \\
\hline Labral tear & Groin & $\begin{array}{l}\text { Abnormal } \\
\text { pain with } \\
\text { examination }\end{array}$ & No & No & No \\
\hline Osteoarthritis & Groin & Abnormal & Possible & Possible & Possible \\
\hline Avascular necrosis & Groin & Varies & Possible & Possible & Possible \\
\hline Snapping hip & Trochanteric & Normal & No & No & Yes \\
\hline $\begin{array}{l}\text { Lumbar } \\
\text { radiculopathy }\end{array}$ & Buttock, leg & Normal & No & No & No \\
\hline Stress fracture & Groin & Varies & No & Yes & Possible \\
\hline $\begin{array}{l}\text { Piriformis } \\
\text { syndrome }\end{array}$ & Posterior & Varies & No & No & Yes \\
\hline
\end{tabular}

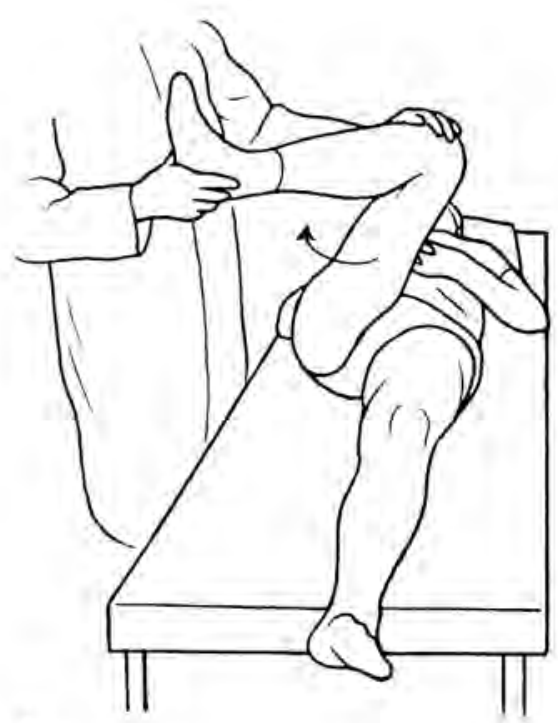

A

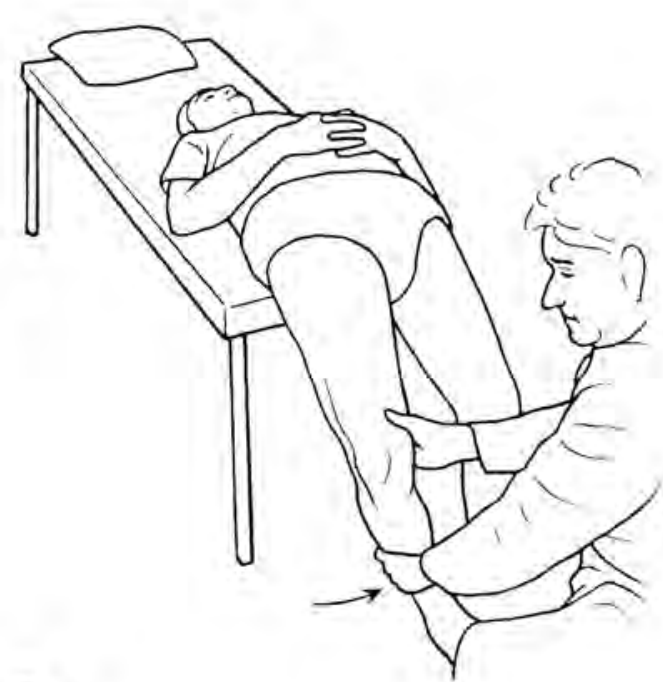

B

Figure 4: (A) The impingement test and (B) the posterior impingement test. @2007 American Academy of Orthopaedic Surgeons. Reprinted from the Journal of the American Academy of Orthopaedic Surgeons volume 15(9), p. 561-70, with permission. ${ }^{6}$ 
lying supine on the examination table. The affected extremity is passively flexed, internally rotated and adducted. Pain is a positive sign of anterior impingement. Martin and Sekiya ${ }^{15}$ showed that the impingement test has moderate to substantial intrarater reliability but low interrater reliability.

The posterior impingement test is a test for posterior cartilage damage and degeneration. ${ }^{4.5} \mathrm{It}$ is performed with the patient supine with both legs dangling off the examination table. The affected hip is abruptly externally rotated. ${ }^{4.5}$ Pain is a positive sign of posterior damage.

\section{Which imaging studies may be helpful?}

Plain radiography of the pelvis and hip is the mainstay of imaging. ${ }^{16}$ This includes a standardized and centred anteroposterior radiograph of the pelvis, and anteroposterior and lateral radiographs of the affected hip., ${ }^{4,5}$ The frontal radiograph should be aligned in such a way that the coccyx is in-line with the symphysis pubis, with about $2 \mathrm{~cm}$ distance between the inferior aspect of the coccyx and the superior border of the symphysis pubis. ${ }^{16}$ Careful examination of the radiographs of the hip joint is required, because changes are often subtle. Consultation with a specialist familiar with imaging in femoroacetabular impingement may be helpful. In particular, the shape of the femoral head and femoral headneck contour should specifically be scrutinized. ${ }^{5}$

Gosvig and colleagues ${ }^{1}$ found that anatomical abnormalities occur more frequently than one might expect. In a cross-sectional study of radiographs of 4151 people in Denmark, the authors found that acetabular overcoverage (pincer impingement) was evident in $15.2 \%$ of men and $19.4 \%$ of women. ${ }^{1}$ Abnormal femoral head and neck anatomy (cam impingement) was reported in $19.6 \%$ of men and $5.2 \%$ of women. ${ }^{1}$ These patients may be asymptomatic, and the number of patients who will develop osteoarthritis is unknown. There may be ethnic variation in the prevalence of femoroacetabular impingement.

Further imaging with magnetic resonance imaging (MRI) is useful for these patients. However, a review before further imaging by a specialist with expertise in this area is helpful for appropriate choice of imaging. Options for MRI include magnetic resonance arthrography (MRA) with an intra-articular injection of contrast under fluoroscopy or nonarthrographic MRI using dedicated femoroacetabular impingement sequences. These 2 techniques may be used to visualize soft-tissue abnormalities that are commonly associated with femoroacetabular impingement, such as labral tears and chondropathic changes that lead to the development of osteoarthritis. These soft-tissue changes are otherwise not reliably visualized on a conventional MRI examination.

\section{What treatments are available?}

For patients with hip pain related to femoroacetabular impingement, both conservative and surgical solutions exist. The present literature is limited to observational studies without controls; randomized trials are needed to further evaluate the treatment of this condition.

Nonsurgical treatment should be initially tried for all patients. Activity modification, including restriction of athletic activities, may be helpful but is often abandoned because affected patients are usually young, active people. Nonsteroidal antiinflammatory drugs may be considered for control of symptoms. A diagnostic and therapeutic hip joint injection of local anesthetic and corticosteroid is another option. Physical therapy regimens with emphasis on increasing range of motion and stretching are sometimes counterproductive and may worsen symptoms. ${ }^{6}$ Only a single study involving 37 patients has been published that reported on conservative treatment for femoroacetabular impingement. ${ }^{17}$ At follow-up after 2 years, 33 of the patients showed improvement in pain and function, but not in range of motion. ${ }^{17}$ Randomized trial data are needed comparing conservative and surgical interventions. If hip pain is not alleviated with nonsurgical management, early orthopedic referral is recommended. 5

There are several surgical options available for patients in whom surgical intervention is recommended. These include correction of acetabular and bony abnormalities with an open procedure and possible hip dislocation; correction of bony abnormalities with hip arthroscopy, pelvic and femoral osteotomies, and hip arthrodesis (although at present this is a rarely employed treatment option); and total hip arthroplasty. ${ }^{4,5}$

The type of procedure chosen depends on the stage of the disease and the patient's age. In a younger patient $(<40 \mathrm{yr})$, joint salvage should be attempted. ${ }^{4}$ Currently, correction of the acetabular or femoral abnormalities may be done through an open surgical approach with a temporary hip dislocation or through arthroscopic techniques. Both have been shown to have excellent short-term results; however, long-term data are lacking. ${ }^{6}$ Surgical treatment with hip arthroscopy will likely become more common with time as skill with arthroscopic techniques improves. ${ }^{4}$ One comprehensive systematic review showed no benefit of open surgical procedures over the more minimally invasive arthroscopic technique. ${ }^{18}$

A systematic review suggested that up to $32 \%$ of patients may continue to have pain after 
treatment with a variety of surgical techniques, including open and arthroscopic approaches and periacetabular osteotomies. ${ }^{19}$ Intra-articular adhesion and advanced cartilage damage are factors suggested to predict failure. Progression of osteoarthritis (defined by conversion to total hip replacement) has been reported in up to $26 \%$ of patients within 3 years. ${ }^{19}$

Hip osteotomy is less commonly used to treat femoroacetabular impingement. In an older patient with more advanced hip degeneration, total hip arthroplasty is a more acceptable option.

\section{Conclusion}

Hip pain is a common symptom seen in primary care and musculoskeletal care clinics. The differential diagnosis should include femoroacetabular impingement, particularly when the patient is a younger adult. Early recognition and orthopedic referral may alter progression toward osteoarthritis.

\section{References}

1. Gosvig KK, Jacobsen S, Sonne-Holm S, et al. Prevalence of malformations of the hip joint and their relationship to sex, groin pain, and risk of osteoarthritis: a population based study. J Bone Joint Surg Am 2010;92:1162-9.

2. Juhakoski R, Heliovaara M, Impivaara O, et al. Risk factors for the development of hip osteoarthritis: a population based prospective study. Rheumatology 2009;48:83-7.

3. Nunley RM, Prather H, Hunt D, et al. Clinical presentation of symptomatic acetabular dysplasia in skeletally mature patients. J Bone Joint Surg Am 2011;93(Suppl 2):17-21.

4. Sierra RJ, Trousdale RT, Ganz R, et al. Hip disease in the young, active patient: evaluation and nonarthroplasty surgical options. J Am Acad Orthop Surg 2008;16:689-703.

5. Samora JB, Ng VY, Ellis TJ. Femoroacetabular impingement: a common cause of hip pain in young adults. Clin J Sport Med 2011;21:51-6.

6. Parvizi J, Leunig M, Ganz R, et al. Femoroacetabular impingement. J Am Acad Orthop Surg 2007;15: 561-70.

7. Beck M, Leunig M, Parvizi J, et al. Anterior femoroacetabular impingement: part II. Midterm results of surgical treatment. Clin Orthop Relat Res 2004;(418):67-73.

8. Herring J. Tachdijian's pediatric orthopaedics. 3rd ed. Philadelphia (PA): WB Saunders; 2002:519-20.

9. Beck M, Kalhor M, Leunig M, et al. Hip morphology influences the pattern of damage to the acetabular cartilage: femoroacetabular impingement as a cause of early osteoarthritis of the hip. J Bone Joint Surg Br 2005;87:1012-8

10. Hartofilakidis G, Bardakos NV, Babis GC, et al. An examination of the association between different morphotypes of femoroacetabular impingement in asymptomatic subjects and the development of osteoarthritis of the hip. J Bone Joint Surg Br 2011;93:580-6.

11. Dagenais S, Garbedian S, Wai EK. Systematic review of the prevalence of radiographic primary hip osteoarthritis. Clin Orthop Relat Res 2009;467:623-37.

12. Plante M, Wallace R, Busconi B. Clinical diagnosis of hip pain. Clin Sports Med 2011;30:225-38.

13. Hasan BA. The presenting symptoms, differential diagnosis, and physical examination of patients presenting with hip pain. Dis Mon 2012;58:477-91.

14. Boyajian-O'Neill LA, McClain RL, Coleman MK, et al. Diagnosis and management of piriformis syndrome: an osteopathic approach. J Am Osteopath Assoc 2008;108:657-64.

15. Martin RL, Sekiya JK. The interrater reliability of 4 clinical tests used to assess individuals with musculoskeletal hip pain. J Orthop Sports Phys Ther 2008;38:71-7.

16. Kappe T, Kocak T, Neuerburg C, et al. Reliability of radiographic signs for acetabular retroversion. Int Orthop 2011;35:817-21.

17. Emara K, Samir W, Motasem EH, et al. Conservative treatment for mild femoroacetabular impingement. J Orthop Surg (Hong Kong) 2011;19:41-5.

18. Bedi A, Chen N, Robertson W, et al. The management of labral tears and femoroacetabular impingement of the hip in the young, active patient. Arthroscopy 2008;24:1135-45.

19. Clohisy JC, St John LC, Schutz AL. Surgical treatment of femoroacetabular impingement: a systematic review of the literature. Clin Orthop Relat Res 2010;468:555-64.

Affiliations: Department of Orthopedic Surgery (Hansen, King); Division of Rheumatology, Department of Medicine (Taylor-Gjevre); Department of Medical Imaging (Obaid), University of Saskatchewan, Saskatoon, Sask.; Division of Orthopaedic Surgery (Gandhi), University of Toronto, Toronto, Ont.

Contributors: Heather Hansen, Regina Taylor-Gjevre and Anthony King were involved in the care of the patient described in the paper, and Haron Obaid reviewed the diagnostic imaging. All of the authors contributed to the writing and revision of the manuscript, and gave final approval of the version submitted for publication. 